\title{
Synthesis and in vitro Anticancer Activity of Novel Heterocycles Utilizing Thiophene Incorporated Thioureido Substituent as Precursors
}

\author{
Marwa Abdel-Motaal, ${ }^{1,2^{\star}}$ Asmaa L. Alanzy ${ }^{2}$ and Medhat Asem ${ }^{3}$ \\ ${ }^{1}$ Department of chemistry, College of Science, Qassim university, Buridah, Qassim, Saudi Arabia \\ ${ }^{2}$ Department of Chemistry, Faculty of Science, Mansoura University, ET-35516 Mansoura, Egypt. \\ ${ }^{3}$ PhD of biochemistry, Faculty of Science, Menoufia University, Menoufia, Egypt. \\ *Corresponding author: E-mail: dr_maroochem@yahoo.com
}

Received: 09-15-2019

\begin{abstract}
Abstract: Ethyl 2-(3-allylthioureido)-4,5,6,7-tetrahydrobenzo[b]thiophene-3-carboxylate (1) was used as a building block for synthesis of new heterocycles. Pyrimidine and thiazole moieties were achieved upon condensation of compound 1 with various reagents such as chloroacetic acid, dietyl malonate, ninhydrin, 2,3-epoxy-2,3-dihydro-1,4-naphthoquinone, and hydrazine hydrate. The structures of the newly synthesized compounds were confirmed using spectral measurements. The prepared products were evaluated for their anticancer activity against colon HCT-116 human cancer cell line. Compounds 6, 9, 10a, 11, 12, 15 have displayed potent activity.
\end{abstract}

Keywords: Tetrahydrobenzo[b]thiophene; thiourea substituent; heterocycles; anticancer activity

\section{Introduction}

Heterocyclic compounds containing thiophene ring have been widely reported to have numerous pharmaceutical importance. For example, such compounds exhibited anticancer, ${ }^{1-4}$ antibacterial, ${ }^{5}$ antifungal, ${ }^{6}$ anti-inflammatory, ${ }^{7}$ anti-ulcer, ${ }^{8}$ anti-diabetic, ${ }^{9}$ antileishmanial, ${ }^{10}$ antimicrobial, ${ }^{11,12}$ antitubercular, ${ }^{13}$ COX-2 selective inhibition, ${ }^{14}$ antiproliferative $^{15}$ activities. Thiophene derivatives were utilized as inhibitors for hepatitis C virus polymerase, ${ }^{16}$ novel BACE1 $1,{ }^{17}$ alkaline phosphatases, ${ }^{18}$ and kinesin spindle protein ${ }^{19}$ and they are more effective in the treatment of Alzheimer's disease. ${ }^{20}$ Moreover, thiophene derivatives have acquired great importance in drug discovery studies ${ }^{21-23}$ which are available in markets, such as methaphenilene that acts as antiallergic agent; tiagabine acts as anticonvulsant agent; Sertaconazole acts as anti-fungal drug and is available as a cream for treatment of skin infections, such as athlete's foot, and the important drug biotin which is used for treating the deficiency of biotin related to pregnancy. The interest in these heterocycles has been attributed to their promising utilization as dye-sensitized solar cells, ${ }^{24}$ organic semiconductors, ${ }^{25}$ potential light-emitting materials for
OLEDs $^{26}$ and in textile dyeing. ${ }^{27,}{ }^{28}$ Accordingly, several methods for the synthesis of thiophene and related heterocycles earn great attention. Normally, the most important method for their preparation is Gewald method involving the reaction of an equimolar amount of elemental sulfur with $\alpha$-methylene ketones and acetonitrile in a basic medium. ${ }^{29,30}$ Polyfunctionalized thiophenes were synthesized via the multicomponent reactions from starting materials, such as $\beta$-ketodithioesters with cyclohexylisocyanide and $\alpha$-haloketones. ${ }^{31}$ Two-step synthesis of benzothiophene derivatives using iodocyclization followed by etherification reaction sequence has been reported. ${ }^{32}$ On the other hand, incorporation of thiourea chain residues was used to obtain key intermediates necessary to produce important heterocyclic compounds. ${ }^{3-35}$ It has been reported that compounds containing pyrimidine ${ }^{36-37}$ and thiazole ${ }^{38-39}$ moieties have potent anticancer activity. According to these facts, we decided to develop the synthesis of new heterocycles utilizing thiophene moiety bearing thioureido chain substituent as a building block and to characterize the prepared products by spectral and analytical techniques. The activity of the newly synthesized heterocyclic compounds against HCT-116 cell lines was tested. 


\section{Experimental}

\subsection{General}

Most reagents and chemicals were purchased, utilized without additional purification, and bought from Sigma-Aldrich. Melting points are uncorrected and an electrothermal apparatus was used for their measurements. The purity of reagents and reaction validation were checked by thin-layer chromatography (TLC) technique on silica gel plates and the spots were imagined under UV light $(254 \mathrm{~nm})$ using mobile phase (pethroleum ether ethyl acetate). Infrared spectra were detected using $\mathrm{KBr}$ discs on Shimadzu FT-IR 8201 PC spectrophotometer. ${ }^{1} \mathrm{H}$ NMR and ${ }^{13} \mathrm{C}$ NMR spectra were recorded on a Bruker instrument at $850 \mathrm{MHz}$ spectrometer using tetramethylsilane (TMS) as an internal standard in $\mathrm{CDCl}_{3}$ or DMSO- $d_{6}$ as solvents; chemical shifts are expressed in $\delta$ (ppm); spectroscopic measurements were carried out in the Microanalysis unit at the Universities of Qassim and Abdul-Aziz (KSA). Mass spectra were recorded on a GCMS-QP1000 EX spectrometer at $70 \mathrm{eV}$. Anticancer analysis was performed at the National cancer institute $(\mathrm{NCl})$, Cairo, Egypt. Starting materials were already prepared according to the reported method. ${ }^{39}$

\section{2. Synthetic Procedures}

Synthesis of 2-((3-Allyl-2-((3-(ethoxycarbonyl)-4,5,6,7 -tetrahydrobenzo $[b]$ thiophen-2-yl)imino)-2,3-dihydrothiazol-4-yl)oxy)acetic acid (4)

A mixture of substitueted thiourea 1 ( $5 \mathrm{mmol})$, monochloroacetic acid $(5 \mathrm{mmol})$ and potassium hydroxide $(5 \mathrm{mmol})$ in methanol $(15 \mathrm{~mL})$ was refluxed at water bath for $8 \mathrm{~h}$. The mixture was left to cool and then poured into ice-water, then acidified with acetic acid. The precipitate that formed was filtered off and recrystallized from methanol to afford 4 as white crystals with yield $88 \%$; $\mathrm{mp}$ 152-153 ${ }^{\circ} \mathrm{C}$. IR $(\mathrm{KBr})\left(v_{\max }, \mathrm{cm}^{-1}\right): 1640,1680(2 \mathrm{C}=\mathrm{O}) .{ }^{1} \mathrm{H}$ $\operatorname{NMR}\left(\mathrm{CDCl}_{3}\right): \delta 1.32\left(\mathrm{t}, 3 \mathrm{H}, \mathrm{CH}_{3}\right), 1.75-1.79(\mathrm{~m}, 4 \mathrm{H}$, $\left.2 \mathrm{CH}_{2}\right), 2.61-2.76\left(\mathrm{~m}, 4 \mathrm{H}, 2 \mathrm{CH}_{2}\right), 3.77\left(\mathrm{~s}, 2 \mathrm{H}, \mathrm{CH}_{2}-\right.$ $\mathrm{COOH}), 3.89\left(\mathrm{~s}, 2 \mathrm{H}, \mathrm{CH}_{2}\right.$ allyl), $4.14(\mathrm{~s}, 1 \mathrm{H},=\mathrm{CH}-\mathrm{S}), 4.24$ $\left(\mathrm{q}, 2 \mathrm{H}, \mathrm{CH}_{2}\right), 4.80(\mathrm{~m}, 1 \mathrm{H},=\mathrm{CH}$ trans allyl $), 5.26-5.29(\mathrm{~m}$, $1 \mathrm{H},=\mathrm{CH}$ cis allyl $), 5.92-5.98\left(\mathrm{~m}, 1 \mathrm{H},=\underline{\mathrm{CH}}-\mathrm{CH}_{2}\right.$ allyl $)$, $11.94(\mathrm{~s}, 1 \mathrm{H}, \mathrm{COOH}) .{ }^{13} \mathrm{C}$ NMR $\left(\mathrm{CHCl}_{3}\right): \delta 14.32,14.41$, $22.86,22.99,23.73,24.36,26.38,60.46,111.27,111.26$, $126.65,130.67,147.65,166.69,166.91$. MS: $m / z(\%) 422$ $\left(\mathrm{M}^{+}, 5\right), 381\left(\mathrm{M}^{+}-\right.$allyl, 20), 365 (100), 223 (60).”

Synthesis of Ethyl 2-(3-Allyl-5-benzylidene)-4-oxothiazolidin-2-ylidene)amino)-4,5,6,7-tetrahydrobenzo[b] thiophene-3-carboxylate (5)

To a solution of compound $\mathbf{1}(5 \mathrm{mmol})$, benzaldehyde (5 mmol) and monochloroacetic acid $(5 \mathrm{mmol})$ in a mixture of acetic anhydride $(5 \mathrm{~mL})$ and acetic acid $(15 \mathrm{~mL})$, fused sodium acetate $(5 \mathrm{mmol})$ was added. The reaction mixture was heated under reflux for $8 \mathrm{~h}$. The mixture was cooled and poured onto crushed ice, the produced solid was filtered off and recrystallized from methanol to afford compound 5 as a yellow powder in yield 75\%; mp $115^{\circ} \mathrm{C}$. IR $(\mathrm{KBr})\left(v_{\max }, \mathrm{cm}^{-1}\right): 1651,1690(2 \mathrm{C}=\mathrm{O}) .{ }^{1} \mathrm{H}$ NMR $\left(\mathrm{CDCl}_{3}\right): \delta 1.40\left(\mathrm{t}, 3 \mathrm{H}, \mathrm{CH}_{3}\right), 1.76\left(\mathrm{~m}, 4 \mathrm{H}, 2 \mathrm{CH}_{2}\right)$, 2.63-2.75 (m, $\left.2 \mathrm{H}, 2 \mathrm{CH}_{2}\right), 5.70$ (s, $2 \mathrm{H}, \mathrm{CH}_{2}$ allyl), 4.31 (q, $\left.2 \mathrm{H}, \mathrm{CH}_{2}\right), 5.20-5.39(\mathrm{~m}, 1 \mathrm{H},=\mathrm{CH}$ trans allyl), 4.45-4.50 $\left(\mathrm{m}, 1 \mathrm{H},=\mathrm{CH}\right.$ cis allyl), $5.92-5.99\left(\mathrm{~m}, 1 \mathrm{H},=\underline{\mathrm{CH}}-\mathrm{CH}_{2}\right.$ allyl $)$, 7.29-7.51 (m, 6H, Ar-H) ${ }^{13}{ }^{2}$ NMR $\left(\mathrm{CDCl}_{3}\right): \delta 14.3,22.8$, $24.4,26.3,34.5,46.4,52.9,60.4,112.3,119.4,130.12$, $130.93,131.2,132.3,134.5,146.7,151.8,155.8,161.6$, 164.6, 166.2, 169.05, 171,01. MS: $m / z(\%) 453\left(\mathrm{M}^{+}, 3\right), 365$ $\left(\mathrm{M}^{+}, 22\right), 268$ (100)."

Synthesis of Ethyl 2-(3-Allyl-4,6-dioxo-2-thioxotetrahydropyrimidin- $1(2 \mathrm{H})$-yl)-4,5,6,7-tetrahydrobenzo $[b]$ thiophene-3-carboxylate (6)

A solution of compound $1(2 \mathrm{mmol})$ and diethyl malonate in sodium ethoxide solution $(2 \mathrm{mmol})$ in $15 \mathrm{~mL}$ of abs. ethanol was heated under reflux for $2 \mathrm{~h}$. After cooling, the formed precipitate was filtered off and dissolved in water and then in ice bath neutralized with hydrochloric acid. The solid product was filtered off, washed with water, and recrystallized from ethanol to give $\mathbf{6}$ as a white precipitate with $85 \%$ yield; $\mathrm{mp} 215-218^{\circ} \mathrm{C}$. IR $(\mathrm{KBr})\left(v_{\max }, \mathrm{cm}^{-1}\right)$ : $1640,1701(3 \mathrm{C}=\mathrm{O}) .{ }^{1} \mathrm{H}$ NMR $\left(\mathrm{CDCl}_{3}\right): \delta 1.25\left(\mathrm{t}, 3 \mathrm{H}, \mathrm{CH}_{3}\right)$, $1.80-1.93\left(\mathrm{~m}, 4 \mathrm{H}, 2 \mathrm{CH}_{2}\right), 2.60-2.90\left(\mathrm{~m}, 2 \mathrm{H}, 2 \mathrm{CH}_{2}\right), 3.88$ (s, $\left.2 \mathrm{H}, \mathrm{CO}-\mathrm{CH}_{2}-\mathrm{CO}\right), 4.31\left(\mathrm{q}, 2 \mathrm{H}, \mathrm{CH}_{2}\right), 5.17-5.27(\mathrm{~m}$, $1 \mathrm{H},=\mathrm{CH}$ trans allyl), $5.32-5.39(\mathrm{~m}, 1 \mathrm{H},=\mathrm{CH}$ cis allyl $)$, $5.78\left(\mathrm{~s}, 2 \mathrm{H}, \mathrm{CH}_{2}\right.$ allyl), 5.92-5.99 (m, $1 \mathrm{H},=\mathrm{CH}-\mathrm{CH}_{2}$ allyl). ${ }^{13} \mathrm{C}$ NMR $\left(\mathrm{CHCl}_{3}\right): \delta 14.32,22.86,22.99,23.73,24.36$, $26.38,60.46,111.27,126.65,130.67,147.65,166.69,166.91$. MS: $m / z(\%) 392\left(\mathrm{M}^{+}, 4\right), 279(80), 223(100) . ”$

\section{General Procedure for the Synthesis of Compounds 7a, $7 \mathrm{~b}$ and 8.}

A mixture of compound $1(2 \mathrm{mmol})$ and appropriate aromatic aldehyde, namely: furfural and benzaldehyde or isatin $(2 \mathrm{mmol})$ was heated at reflux in $\mathrm{EtOH}(15 \mathrm{~mL})$ containing a few drops of piperidine for $7 \mathrm{~h}$. The solvent was evaporated till half of its volume. The solid that formed was filtered off and recrystallized from appropriate solvent to give the corresponding final products $7 \mathbf{a}, 7 \mathbf{b}$ and $\mathbf{8 .}$

Ethyl 2-(3-Allyl-5-(furan-2-ylmethylene)-4,6-dioxo-2 -thioxotetrahydropyrimidin-1(2H)-yl)-4,5,6, 7-tetrahydrobenzo $[b]$ thiophene-3-carboxylate (7a)

Brown powder, yield $58 \%$; mp $155-156{ }^{\circ} \mathrm{C}(\mathrm{EtOH})$; IR $(\mathrm{KBr})\left(v_{\max }, \mathrm{cm}^{-1}\right): 1642,1670(2 \mathrm{C}=\mathrm{O}) .{ }^{1} \mathrm{H}$ NMR $\left(\mathrm{CDCl}_{3}\right): \delta 1.80\left(\mathrm{~m}, 7 \mathrm{H}, \mathrm{CH}_{3}, 2 \mathrm{CH}_{2}\right), 2.68\left(\mathrm{t}, 2 \mathrm{H}, \mathrm{CH}_{2}\right)$, $2.92\left(\mathrm{t}, 2 \mathrm{H}, \mathrm{CH}_{2}\right), 3.90\left(\mathrm{~s}, 2 \mathrm{H}, \mathrm{CH}_{2}\right.$ allyl), $4.38(\mathrm{q}, 2 \mathrm{H}$, $\left.\mathrm{CH}_{2}\right), 5.24-5.28(\mathrm{~m}, 1 \mathrm{H},=\mathrm{CH}$ trans allyl), 5.34-5.36 (m, $1 \mathrm{H},=\mathrm{CH}$ cis allyl $), 5.96-6.013\left(\mathrm{~m}, 1 \mathrm{H},=\underline{\mathrm{CH}}-\mathrm{CH}_{2}\right.$ allyl $)$, $7.01(\mathrm{~m}, 3 \mathrm{H}, \mathrm{H}-\mathrm{Ar}), 8.22(\mathrm{~s}, 1 \mathrm{H}, \mathrm{CH}=) .{ }^{13} \mathrm{C} \mathrm{NMR}\left(\mathrm{CHCl}_{3}\right)$ : $\delta 21.8,22.9,24.6,25.25,48.24,48.47,117.04,118.69$, $129.02,130.71,131.6,132.52,137.9,144.1,147.75,157.68$,

Abdel-Motaal et al.: Synthesis and in vitro Anticancer Activity ... 
159.96, 161.56, 173.88. MS: $m / z(\%) 476\left(\mathrm{M}^{+}+5,15\right), 289$ (48), 210 (50), 139 (22), 86 (100)."

Ethyl 2-(3-Allyl-5-benzylidene-4,6-dioxo-2-thioxotetrahydropyrimidin-1 $(2 \mathrm{H})$-yl)-4,5,6,7-tetrahydrobenzo[b] thiophene-3-carboxylate (7b)

Yellow crystals; yield $66 \%$; mp $205-208{ }^{\circ} \mathrm{C}$ (dil. EtOH), IR (KBr) $\left(v_{\max }, \mathrm{cm}^{-1}\right): 1640,1710(2 \mathrm{C}=\mathrm{O}) .{ }^{1} \mathrm{H}$ NMR $\left(\mathrm{CDCl}_{3}\right): \delta 0.86\left(\mathrm{t}, 3 \mathrm{H}, \mathrm{CH}_{3}\right), 1.79-1.90\left(\mathrm{~m}, 4 \mathrm{H}, 2 \mathrm{CH}_{2}\right)$, $2.67\left(\mathrm{t}, 2 \mathrm{H}, \mathrm{CH}_{2}\right), 2.91\left(\mathrm{t}, 2 \mathrm{H}, \mathrm{CH}_{2}\right), 4.07\left(\mathrm{q}, 2 \mathrm{H}, \mathrm{CH}_{2}\right)$, 4.16-4.30 $\left(\mathrm{m}, 1 \mathrm{H},=\mathrm{CH}\right.$ trans allyl), $5.10\left(\mathrm{~s}, 2 \mathrm{H}, \mathrm{CH}_{2}\right.$ allyl $)$, $5.20-5.35(\mathrm{~m}, 1 \mathrm{H},=\mathrm{CH}$ cis allyl $), 5.93-6.00(\mathrm{~m}, 1 \mathrm{H},=\mathrm{CH}-$ $\mathrm{CH}_{2}$ allyl), 7.40-7.80 (m, 5H, Ar-H), $8.10(\mathrm{~s}, 1 \mathrm{H}) .{ }^{13} \mathrm{C} \mathrm{NMR}$ $\left(\mathrm{CHCl}_{3}\right): \delta 20.6,22.09,22.9,24.6,25.22,29.7,48.4,117.04$, $118.62,128.4,129.11,130.7,130.2,131.17,132.3,133.6$, $136.4,147.95,156.58,169.85,173.83$. MS: $m / z(\%) 481\left(\mathrm{M}^{+}\right.$, 3), $454\left(\mathrm{M}^{+}-\mathrm{CH}=\mathrm{CH}_{2}, 8\right), 275$ (95), 68 (100), 324 (40)."

Ethyl 2-(3-Allyl-4,6-dioxo-5-(2-oxoindolin-3-ylidene) -2-thioxotetrahydropyrimidin-1(2H)-yl)-4,5,6,7-tetrahydrobenzo $[b]$ thiophene-3-carboxylate $(8)$

Deep yellow powder; yield $55 \%$; mp $170-173{ }^{\circ} \mathrm{C}$ (dil. EtOH); IR (KBr) $\left(v_{\max }, \mathrm{cm}^{-1}\right): 3234(\mathrm{NH}), 1655,1645$, $1634(4 \mathrm{C}=\mathrm{O}) .{ }^{1} \mathrm{H}$ NMR $\left(\mathrm{CDCl}_{3}\right): \delta 1.20\left(\mathrm{t}, 3 \mathrm{H}, \mathrm{CH}_{3}\right), 1.80$ $\left(\mathrm{m}, 4 \mathrm{H}, 2 \mathrm{CH}_{2}\right), 2.96\left(\mathrm{t}, 2 \mathrm{H}, \mathrm{CH}_{2}\right), 2.73\left(\mathrm{t}, 2 \mathrm{H}, \mathrm{CH}_{2}\right), 4.36$ (q, $\left.2 \mathrm{H}, \mathrm{CH}_{2}\right), 4.40-4.70(\mathrm{~m}, 1 \mathrm{H},=\mathrm{CH}$ trans allyl), $4.80(\mathrm{~s}$, $2 \mathrm{H}, \mathrm{CH}_{2}$ allyl), 5.09-5.34 (m, $1 \mathrm{H},=\mathrm{CH}$ cis allyl), 5.90-5.99 $\left(\mathrm{m}, 1 \mathrm{H},=\mathrm{CH}-\mathrm{CH}_{2}\right.$ allyl), 6.90-7.60 (m, 4H, Ar-H), $8.10(\mathrm{~s}$, $1 \mathrm{H}, \mathrm{NH}) .{ }^{13} \mathrm{C}$ NMR $\left(\mathrm{CHCl}_{3}\right): \delta 112.25,116.88,118.39$, $123.11125 .8,128.7,131.2,132.5,138.6,144.12,147.8$, $149.09,157.7,158.9,159.99,161.62,174.15$. MS: $m / z(\%)$ $521\left(\mathrm{M}^{+}, 20\right), 365(30), 268(100) . "$

Synthesis of Ethyl 2-(3-Allyl-4,6-dioxo-2-thioxo-5-((paratolylamino)methyl)tetrahydropyrimidin-1 $(2 \mathrm{H})$-yl) $-4,5,6,7$-tetrahydrobenzo $[b]$ thiophene-3-carboxylate (9)

A mixture of $6(0.01 \mathrm{~mol})$ and $\mathrm{HCHO}(2 \mathrm{~mL})$ in $\mathrm{EtOH}(10 \mathrm{~mL})$ was warmed for $10 \mathrm{~min}$; after the addition of para-toluidine $(0.01 \mathrm{~mol})$, the mixture was refluxed for $3 \mathrm{~h}$ and cooled. The solid that formed was filtered off and then recrystallized from ethanol to give white crystals of 9 in $72 \%$ yield; $\mathrm{mp} 223-225^{\circ} \mathrm{C}$; IR $(\mathrm{KBr})\left(v_{\max }, \mathrm{cm}^{-1}\right)$ : 1640 , $1710(2 \mathrm{C}=\mathrm{O}) .{ }^{1} \mathrm{H}$ NMR $\left(\mathrm{CDCl}_{3}\right): \delta 0.86\left(\mathrm{t}, 3 \mathrm{H}, \mathrm{CH}_{3}\right)$, $1.79-1.90\left(\mathrm{~m}, 4 \mathrm{H}, 2 \mathrm{CH}_{2}\right), 2.67\left(\mathrm{t}, 2 \mathrm{H}, \mathrm{CH}_{2}\right), 2.91(\mathrm{t}, 2 \mathrm{H}$, $\left.\mathrm{CH}_{2}\right), 4.07\left(\mathrm{q}, 2 \mathrm{H}, \mathrm{CH}_{2}\right), 4.16-4.30(\mathrm{~m}, 1 \mathrm{H},=\mathrm{CH}$ trans allyl), $5.10\left(\mathrm{~s}, 2 \mathrm{H}, \mathrm{CH}_{2}\right.$ allyl), $5.20-5.35(\mathrm{~m}, 1 \mathrm{H},=\mathrm{CH}$ cis allyl), 5.93-6.00 (m, $1 \mathrm{H},=\mathrm{CH}-\mathrm{CH}_{2}$ allyl), $7.40-7.80(\mathrm{~m}, 5 \mathrm{H}$, Ar-H), $8.10(\mathrm{~s}, 1 \mathrm{H}, \mathrm{NH}) .{ }^{13} \mathrm{C}$ NMR $\left(\mathrm{CHCl}_{3}\right): \delta 13.98,18.44$, 21.9, 22.9, 24.68, 25.24, 25.48, 48.46, 85.54, 68.32, 117.06, 118.6, 129.08, 130.73, 132.47, 147.81, 156.53, 173.83. MS: $\mathrm{m} / z(\%) 438\left(\mathrm{M}^{+}\right.$- COOEt, 20), 263 (100), 278 (34).”

General Procedure for the Synthesis of Compounds 10a and 10b

A diazonium solution was prepared by dissolving (0.02 mol) of para-toluidine or 4-aminobenzophenone in
$30 \mathrm{~mL}$ water and $6 \mathrm{~mL}$ concentrated $\mathrm{HCl}$; this solution was cooled to $0{ }^{\circ} \mathrm{C}$. The solution was then treated with $0.02 \mathrm{~mol}$ sodium nitrite in $20 \mathrm{~mL}$ of water, were added gradually with stirring for $30 \mathrm{~min}$ with cooling in an ice bath to complete the diazotization. The formed diazonium chloride was slowly added to compound $\mathbf{6}$ in pyridine with stirring at $0-5{ }^{\circ} \mathrm{C}$ for $2 \mathrm{~h}$. The mixture was added with stirring to ice-cold water. The resulting solid was filtered off, dried and recrystallized from methanol."

Ethyl (Z)-2-(3-Allyl-4,6-dioxo-2-thioxo-5-(2-(para-tolyl)hydrazono) tetrahydropyrimidin- $1(2 H)-y l)-4,5$, 6,7-tetrahydrobenzo[b] thiophene-3-carboxylate (10a)

Reddish brown powder; yield $85 \%$; $\mathrm{mp} 206-208^{\circ} \mathrm{C}$; IR (KBr) $\left(v_{\max }, \mathrm{cm}^{-1}\right): 3246(\mathrm{NH}), 1640(\mathrm{C}=\mathrm{O}) .{ }^{1} \mathrm{H}$ NMR $\left(\mathrm{CDCl}_{3}\right): \delta 1.20\left(\mathrm{t}, 3 \mathrm{H}, \mathrm{CH}_{3}\right), 1.80\left(\mathrm{~m}, 4 \mathrm{H}, 2 \mathrm{CH}_{2}\right), 2.96(\mathrm{t}$, $\left.2 \mathrm{H}, \mathrm{CH}_{2}\right), 2.73\left(\mathrm{t}, 2 \mathrm{H}, \mathrm{CH}_{2}\right), 4.36\left(\mathrm{q}, 2 \mathrm{H}, \mathrm{CH}_{2}\right), 4.40-4.70$ ( $\mathrm{m}, 1 \mathrm{H},=\mathrm{CH}$ trans allyl), $4.80\left(\mathrm{~s}, 2 \mathrm{H}, \mathrm{CH}_{2}\right.$ allyl), 5.09-5.34 $(\mathrm{m}, 1 \mathrm{H},=\mathrm{CH}$ cis allyl $), 5.90-5.99\left(\mathrm{~m}, 1 \mathrm{H},=\mathrm{CH}-\mathrm{CH}_{2}\right.$ allyl $)$, 6.90-7.60 (m, 4H, Ar-H), 8.10 (s, $1 \mathrm{H}, \mathrm{NH}) .{ }^{13} \mathrm{C}$ NMR $\left(\mathrm{CHCl}_{3}\right): \delta 21.95,22.2,22.9,24.6,29.71,48.92,62.2,64.14$, 77.04, 116.9, 118.3, 129.03, 129.56, 130.02, 130.4, 130.7, $131.18,132.2,135.56,148.38,156.7,161.7,171.5,172.3$, 173.9. MS: $m / z(\%) 521\left(\mathrm{M}^{+}, 20\right), 365$ (30), 268 (100)."

Ethyl (Z)-2-(3-Allyl-5-(2-(4-benzoylphenyl)hydrazono)-4,6-dioxo-2-thioxotetrahydropyrimidin-1 $(2 H)$-yl) $-4,5,6,7$-tetrahydrobenzo $[b]$ thiophene-3-carboxylate (10b)

Reddish brown powder; yield $82 \%$; $\mathrm{mp} 160-161^{\circ} \mathrm{C}$; IR $(\mathrm{KBr})\left(v_{\max }, \mathrm{cm}^{-1}\right): 3247(\mathrm{NH}), 1716,1639(\mathrm{C}=\mathrm{O}) .{ }^{1} \mathrm{H}$ $\operatorname{NMR}\left(\mathrm{CDCl}_{3}\right): \delta 1.42\left(\mathrm{t}, 3 \mathrm{H}, \mathrm{CH}_{3}\right), 1.76-1.82(\mathrm{~m}, 4 \mathrm{H}$, $\left.2 \mathrm{CH}_{2}\right), 2.63-2.90\left(\mathrm{~m}, 4 \mathrm{H}, 2 \mathrm{CH}_{2}\right), 4.43\left(\mathrm{q}, 2 \mathrm{H}, \mathrm{CH}_{2}\right), 4.86$ (s, $2 \mathrm{H}, \mathrm{CH}_{2}$ allyl), $5.079-5.22(\mathrm{~m}, 1 \mathrm{H},=\mathrm{CH}$ trans allyl), 5.92-6.00 $(\mathrm{m}, 1 \mathrm{H},=\mathrm{CH}$ cis allyl $), 5.20\left(\mathrm{~m}, 1 \mathrm{H},=\mathrm{CH}-\mathrm{CH}_{2}\right.$ allyl), 7.42-7.90 (m, 7H, Ar-H), 8.40 (s, 1H, Ar-H), 8.90 (s, $1 \mathrm{H}, \mathrm{Ar}-\mathrm{H}), 12.70(\mathrm{~s}, 1 \mathrm{H}$, broad NH$) .{ }^{13} \mathrm{C} \mathrm{NMR}\left(\mathrm{CHCl}_{3}\right): \delta$ $14.13,22.2,22.9,25.4,29.7,62.03,46.3,118.16,116.8$, 126.9-134.69 (Ar-C), 163.4, 172.6, 173.79, 195.9, 196.8. MS: $m / z(\%) 600\left(\mathrm{M}^{+}, 13\right), 554(10), 406$ (8), 278 (34), 263 (100)."

Synthesis of Ethyl (Z)-2-((1-Allyl-4,5-dioxo-4,5-dihydronaphtho $[1,2-d]$ thiazol-2(1H)-ylidene)amino)-4,5, 6,7-tetrahydrobenzo $[b]$ thiophene-3-carboxylate (12)

A mixture of compound $\mathbf{1}(0.01 \mathrm{~mol})$ and 2,3-dihydro-2,3-epoxy-1,4-naphthoquinone $(0.01 \mathrm{~mol})$ in ethanol $(20 \mathrm{~mL})$ was refluxed for $5 \mathrm{~h}$ in water bath. After cooling, the precipitate that formed was isolated, dryed and then dissolved in $15 \mathrm{~mL}$ of water. The formed solution was neutralized with dil. $\mathrm{HCl}$ with stirring in ice bath. The resulted solid was filtered off and recrystallized from methanol to afford 12 as a reddish brown powder in $93 \%$ yield; $\mathrm{mp}$ 258-260 ${ }^{\circ} \mathrm{C}$. IR (KBr) $\left(v_{\max }, \mathrm{cm}^{-1}\right): 1689,1680,1668$ $(3 \mathrm{C}=\mathrm{O}) .{ }^{1} \mathrm{H}$ NMR $\left(\mathrm{CDCl}_{3}\right): \delta 1.24\left(\mathrm{t}, 3 \mathrm{H}, \mathrm{CH}_{3}\right), 1.20-1.30$ $\left(\mathrm{m}, 4 \mathrm{H}, 2 \mathrm{CH}_{2}\right), 1.60-1.70\left(\mathrm{~m}, 4 \mathrm{H}, 2 \mathrm{CH}_{2}\right), 4.27(\mathrm{q}, 2 \mathrm{H}$,

Abdel-Motaal et al.: Synthesis and in vitro Anticancer Activity ... 
$\left.\mathrm{CH}_{2}\right), 4.12-4.25(\mathrm{~m}, 1 \mathrm{H},=\mathrm{CH}$ trans allyl $), 5.08-5.22(\mathrm{~m}$, $3 \mathrm{H},=\mathrm{CH}$ trans allyl, $\mathrm{CH}_{2}$ allyl $), 5.80-5.90(\mathrm{~m}, 1 \mathrm{H},=\mathrm{CH}$ cis allyl), 7.80-8.50 (m, 4H, Ar-H). ${ }^{13} \mathrm{C} \mathrm{NMR}\left(\mathrm{CHCl}_{3}\right): \delta 14.1$, $22.4,118.5,125.9,126.2,125.4,125.99,126.24,129.97$, $130.6,131.9,133.62,134.5,134.64,156.3,178.7,180.8$, 181.3. MS: $m / z(\%) 478\left(\mathrm{M}^{+}, 4\right), 353$ (20), 226 (100)."

Synthesis of Ethyl (Z)-2-((3-Allyl-3a,8a-dihydroxy-8oxo-3,3a,8,8a-tetrahydro- $2 \mathrm{H}$-indeno $[1,2-d]$ thiazol-2ylidene)amino)-4,5,6,7-tetrahydrobenzo $[b]$ thiophene-3-carboxylate (13)

A mixture of compound $1(0.01 \mathrm{~mol})$ and ninhydrin $(0.01 \mathrm{~mol})$ in $\mathrm{AcOH}(15 \mathrm{~mL})$ was refluxed with stirring at $85^{\circ} \mathrm{C}$ for $5 \mathrm{~h}$. After cooling, the mixture was poured into cold water. The precipitate that formed was filtered off, dried and crystallized from ethanol to afford 13 as a reddish brown powder in $66 \%$ yield; $\mathrm{mp} 170-172{ }^{\circ} \mathrm{C}$. IR $(\mathrm{KBr})\left(v_{\max }, \mathrm{cm}^{-1}\right): 1640,1680(2 \mathrm{C}=\mathrm{O}) .{ }^{1} \mathrm{H} \mathrm{NMR}\left(\mathrm{CDCl}_{3}\right)$ : $\delta 1.38\left(\mathrm{t}, 3 \mathrm{H}, \mathrm{CH}_{3}\right), 1.81-1.86\left(\mathrm{~m}, 4 \mathrm{H}, 2 \mathrm{CH}_{2}\right), 2.70-2.73$ $\left(\mathrm{m}, 4 \mathrm{H}, 2 \mathrm{CH}_{2}\right), 4.34(\mathrm{~m}, 1 \mathrm{H},=\mathrm{CH}-\mathrm{S}), 4.39\left(\mathrm{q}, 2 \mathrm{H}, \mathrm{CH}_{2}\right)$, 4.50-4.70 (m, 1H, =CH trans allyl), 5.17-5.30 $(\mathrm{m}, 1 \mathrm{H}$, $=\mathrm{CH}$ cis allyl), $5.95-5.98\left(\mathrm{~m}, 1 \mathrm{H},=\underline{\mathrm{CH}}-\mathrm{CH}_{2}\right.$ allyl), $7.50(\mathrm{~s}$, $2 \mathrm{H}, 2 \mathrm{OH}), 7.62-7.93(\mathrm{~m}, 4 \mathrm{H}, \mathrm{Ar}-\mathrm{H}) .{ }^{13} \mathrm{C} \mathrm{NMR}\left(\mathrm{CHCl}_{3}\right)$ : $\delta 11.45,14.12,22.4,25.3,26.2,46.3,62.52,89.4,93.01$, $117.3,125.01,125.34,126.46,131.23,131.55,132.72$, $136.6,137.09,137.63,147.6,166.2,166.5,180.4,180.7$, 193.2, 193.9. MS: $m / z(\%) 484\left(\mathrm{M}^{+}, 2\right), 322.9\left(\mathrm{M}^{+}, 58\right), 260$ (13), 277 (100).”

Synthesis of 4-Allyl-1-phenyl-6,7,8,9-tetrahydrobenzo[ $[4,5]$ thieno $[3,2-e][1,2,4]$ triazolo $[4,3-a]$ pyrimidin-5 (4H)-one (14)

A mixture of compound $\mathbf{1}(0.01 \mathrm{~mol})$ and the benzoyl hydrazide $(0.01 \mathrm{~mol})$ was heated under reflux for $12 \mathrm{~h}$ in ethanol $(15 \mathrm{~mL})$ in the presence of a few drops of $\mathrm{AcOH}$. The mixture was left to cool. The precipitate that formed was filtered off and then recrystallized from $\mathrm{EtOH}$ to give 14 as white needles in $93 \%$ yield; $\mathrm{mp} 267-270{ }^{\circ} \mathrm{C}$. IR ( $\left.\mathrm{KBr}\right)$ $\left(v_{\max }, \mathrm{cm}^{-1}\right): 1641,1735(2 \mathrm{C}=\mathrm{O}) .{ }^{1} \mathrm{H} \mathrm{NMR}\left(\mathrm{CDCl}_{3}\right): \delta$ 1.79-1.87 (m, 4H, 2CH $\mathrm{CH}_{2}$, $2.68\left(\mathrm{t}, 2 \mathrm{H}, \mathrm{CH}_{2}\right), 2.92(\mathrm{t}, 2 \mathrm{H}$, $\left.\mathrm{CH}_{2}\right), 4.80\left(\mathrm{~m}, 2 \mathrm{H}, \mathrm{CH}_{2}\right.$ allyl $), 5.10(\mathrm{~m}, 1 \mathrm{H},=\mathrm{CH}$ trans allyl), 5.24-5.36 (m, 1H, =CH cis allyl), 5.96-6.01 (m, $1 \mathrm{H}$, $=\underline{\mathrm{CH}}-\mathrm{CH}_{2}$ allyl $), 7.20-7.80(\mathrm{~m}, 5 \mathrm{H}, \mathrm{Ar}-\mathrm{H}) \cdot{ }^{13} \mathrm{C} \mathrm{NMR}$ $\left(\mathrm{CHCl}_{3}\right): \delta 21.89,22.9,24.6,25.25,48.48,117.03,118.67$, $125.8,129.0,130.72,131.81,132.52,147.7,156.5,173.88$. MS: $m / z(\%) 362\left(\mathrm{M}^{+}, 5\right), 324\left(\mathrm{M}^{+}, 22\right), 263(92), 179$ (100)."

Synthesis of 3-Allyl-2-mercapto-5,6,7,8-tetrahydrobenzo[4,5] thieno[2,3-d]pyrimidin-4(3H)-one (15)

A solution of compound 1 (0.01 mol) in DMF (15 $\mathrm{mL})$ in the presence of $\mathrm{KOH}(0.01 \mathrm{~mol})$ was stirred overnight. The mixture was poured onto crushed ice with stirring. The precipitate that formed was filtered off, dried and recrystallized from $\mathrm{EtOH}$ to give $\mathbf{1 5}$ as white crystals in $85 \%$ yield $85 \%$; mp $235-236^{\circ} \mathrm{C}$."
Synthesis of $N^{\prime}$-(3-Allyl-4-oxo-3,4,5,6,7,8-hexahydrobenzo $[4,5]$ thieno $[2,3-d]$ pyrimidin-2-yl)benzohydrazide (16)

Thienopyrimidine derivative $15(0.01 \mathrm{~mol})$ was heated under reflux with benzoyl hydrazide $(0.01 \mathrm{~mol})$ in ethanol for $28 \mathrm{~h}$. After cooling, the resulted solid was isolated, dried and recrystallized from ethanol to afford 16 as white crystals in $65 \%$ yield; mp $177-178{ }^{\circ} \mathrm{C}$. IR (KBr) ( $v_{\max }$, $\left.\mathrm{cm}^{-1}\right)$ : 3251, $3397(2 \mathrm{NH}), 1689,1670,1642(4 \mathrm{C}=\mathrm{O}) .{ }^{1} \mathrm{H}$ NMR $\left(\mathrm{CDCl}_{3}\right): \delta 1.76-1.81\left(\mathrm{~m}, 4 \mathrm{H}, 2 \mathrm{CH}_{2}\right), 2.60-2.92(\mathrm{~m}$, $\left.4 \mathrm{H}, 2 \mathrm{CH}_{2}\right), 4.89\left(\mathrm{~m}, 2 \mathrm{H}, \mathrm{CH}_{2}\right.$ allyl), $4.08(\mathrm{~S}, 1 \mathrm{H}, \mathrm{NH}), 5.10$ $(\mathrm{m}, 1 \mathrm{H},=\mathrm{CH}$ trans allyl $), 5.26-5.34(\mathrm{~m}, 1 \mathrm{H},=\mathrm{CH}$ cis allyl $)$, 5.96-6.01 (m, 1H, = $\underline{\mathrm{CH}}-\mathrm{CH}_{2}$ allyl), 7.40-7.90 (m, 7H, Ar$\left.\mathrm{H}, \mathrm{NH}_{2}\right) .{ }^{13} \mathrm{C} \mathrm{NMR}\left(\mathrm{CHCl}_{3}\right): \delta 21.8,22.9,24.6,48.2,48.48$, $117.05,118.65,129.02,130.4,130.7,131.62,132.31,132.52$, $137.92,144.11,147.75,156.52,157.68,159.97,161.56$, 173.88. MS: $m / z(\%) 408\left(\mathrm{M}^{+}+28,0.18\right), 278(30), 263$ (100)."

\section{General Method for Synthesis of 17 and 18}

Compound 1 (0.01 mol) was mixed with hydrazine hydrate $(0.015 \mathrm{~mol})$ in ethanol $(30 \mathrm{~mL})$. The resulting solution was refluxed for $8 \mathrm{~h}$. After cooling, the precipitate that formed was filtered off and crystallized to give $\mathbf{1 8}$ as bright white needles; yield $90 \%$; mp $280-283{ }^{\circ} \mathrm{C}$. The filtrate was evaporated till $10 \mathrm{~mL}$ and then was left overnight to cool. The formed solid was filtered off, dried and crystallized from $\mathrm{EtOH}$ to give $\mathbf{1 7}$ as white crystals; yield 82\%; mp $198-199{ }^{\circ} \mathrm{C}(\mathrm{EtOH})$.”

3-Allyl-2-hydrazinyl-5,6,7,8-tetrahydrobenzo[ $[4,5]$ thieno[2,3-d]pyrimidin-4(3H)-one $(17)^{43}$ and 3-Methyl-1,2, $3,4,7,8,9,10$-octahydro- $6 H$-benzo $\left[4^{\prime}, 5^{\prime}\right]$ thieno $\left[2,3^{\prime}: 4,5\right]$ pyrimido[2,1-c] $[1,2,4]$ triazin-6-one (18)

IR $(\mathrm{KBr})\left(v_{\max }, \mathrm{cm}^{-1}\right): 3239(\mathrm{NH}), 1638(\mathrm{C}=\mathrm{O}) .{ }^{1} \mathrm{H}$ NMR $\left(\mathrm{CDCl}_{3}\right): \delta 1.02\left(\mathrm{~m}, 2 \mathrm{H}, \mathrm{CH}_{2}-3\right), 1.79-1.80(\mathrm{~m}, 4 \mathrm{H}$, $\left.2 \mathrm{CH}_{2}\right), 2.68\left(\mathrm{t}, 2 \mathrm{H}, \mathrm{CH}_{2}\right), 2.92\left(\mathrm{t}, 2 \mathrm{H}, \mathrm{CH}_{2}\right), 4.17(\mathrm{t}, 2 \mathrm{H}$, $\left.\mathrm{CH}_{2}-2\right), 4.37\left(\mathrm{t}, 2 \mathrm{H}, \mathrm{CH}_{2}-4\right), 8.80\left(\mathrm{~s}, 2 \mathrm{H}, \mathrm{NH}_{2}\right) .{ }^{13} \mathrm{C} \mathrm{NMR}$ $\left(\mathrm{CHCl}_{3}\right): \delta 11.3,21.9,22.9,24.7,25.2,25.4,48.3,123.2$, 137.6, 143.9, 157.8, 159.8, 161.5. MS: $m / z(\%) 280\left(\mathrm{M}^{+}+2\right.$, 100), $278\left(\mathrm{M}^{+}, 30\right), 263$ (62), $179(71)$.

\section{3. Cytotoxic Activity}

Cytotoxicity of the synthesized compounds was evaluated against HCT-116 (colon adenocarcinoma) using MTT assay. ${ }^{44}$ The prepared compounds were dissolved in DMSO (dimethylsulfoxide) and diluted 1000-times during the test. It is essential to enable cells to be attached to the wall of the plate. Prior to the treatment with the tested compounds, these cell lines were plated in 96-multi well plate $\left(10^{4}\right.$ cells/well) for $24 \mathrm{~h}$. Each well was supplemented with $100 \mu \mathrm{g} / \mathrm{mL}$ of the tested compounds. Under a $5 \% \mathrm{CO}_{2}$ atmosphere, the monolayer cells were incubated with the samples at $37^{\circ} \mathrm{C}$ for $72 \mathrm{~h}$. Then, $20 \mu \mathrm{L}$ of MTT solution at $5 \mathrm{mg} / \mathrm{mL}$ has been added and incubated for $4 \mathrm{~h}$ after $24 \mathrm{~h}$ 
of drug treatment. The colorimetric assay is evaluated and registered using a plate reader at $570 \mathrm{~nm}$ absorbance. Determination of $\mathrm{IC}_{50}$ (the half-maximal inhibitory concentration) for three samples of the most potent inhibitions. Calculation of $\mathrm{IC}_{50}$ values along with the respective $95 \%$ confidence intervals by plotting the relationship between the surviving fraction and the sample concentration to obtain the cancer cell line survival curve.

\section{Results and Discussion}

\section{1. Chemistry}

Our target was to convert the open-chain thiourea substituent 1 into heterocycles to enhance their biological activity. The building block thiourea derivative $\mathbf{1}$ was synthesized through multicomponent synthetic route starting by Gewald reaction of ethyl cyanoacetate with cyclohexanone in the presence of elemental sulfur and then subsequent treatment of $\mathbf{1}$ with allyl thiocyanate. ${ }^{40}$ Spectral and analytical data of the synthesized thiourea intermediate were compatible with reported results. Refluxing of 1 with chloroacetic acid in the presence of potassium hydroxide has unexpectedly afforded the corresponding thiazole derivative $\mathbf{4}$ rather than the thiazolidinone derivative $\mathbf{2}^{40}$ while it was expected that the formation of 2 through the reaction as the intermediate would be possible.

The mechanism suggested for the creation of 4 begins with the electronegative sulfur attack on the active methylene group which is an electron-deficient carbon, followed by cyclization to form thiazolidinone intermediate 2. Keto-enol tautomerism leads to enol form and then $O$-alkylation with another molecule of chloroacetic acid takes place. The spectral data of $\mathbf{4}$ supported our explanations (Scheme 1). IR spectrum of 4 revealed the disappearance of $\mathrm{NH}$ absorption band. ${ }^{1} \mathrm{H}$ NMR spectrum confirmed the structure while it showed the presence of a singlet signal at $11.9 \mathrm{ppm}$ due to $-\mathrm{COOH}$ group beside the other signals of the compound. Also, its ${ }^{13} \mathrm{C}$ NMR spectral data revealed the presence of 19 signals. Mass spectrum showed molecular ion peak at $\mathrm{m} / z \mathrm{M}^{+}-\mathrm{CO}_{2} 381$ (20\%) with a base peak at $m / z 365$ due to $\mathrm{M}^{+}-\mathrm{CH}_{2} \mathrm{COOH}$ fragment. One-pot reaction of $\mathbf{1}$ by cyclocondensation with chloroacetic acid and benzaldehyde in boiling acetic acid and acetic anhydride in the presence of sodium acetate produced the benzylidene-thiazolidinone 5 in good yield. Spectral data have confirmed its structure. ${ }^{1} \mathrm{H}$ NMR spectrum revealed the appearance of multiplet signals at 7.29$7.51 \mathrm{ppm}$ due to the phenyl ring protons.

Cyclocondesation of the thiourea derivative $\mathbf{1}$ with diethyl malonate in the presence of sodium ethoxide in ethanol formed the pyrimidinone derivative 6. Structure of 6 was confirmed using IR, NMR and mass spectra. IR spectrum showed significant stretching bands at 1639 $\mathrm{cm}^{-1}$ due to the amidic carbonyls beside the lack of $\mathrm{NH}$ absorption bands. Its ${ }^{1} \mathrm{H}$ NMR spectrum accentuated the presence of singlet signal at $3.88 \mathrm{ppm}$ due to the methylene protons in addition to the other expected signals.

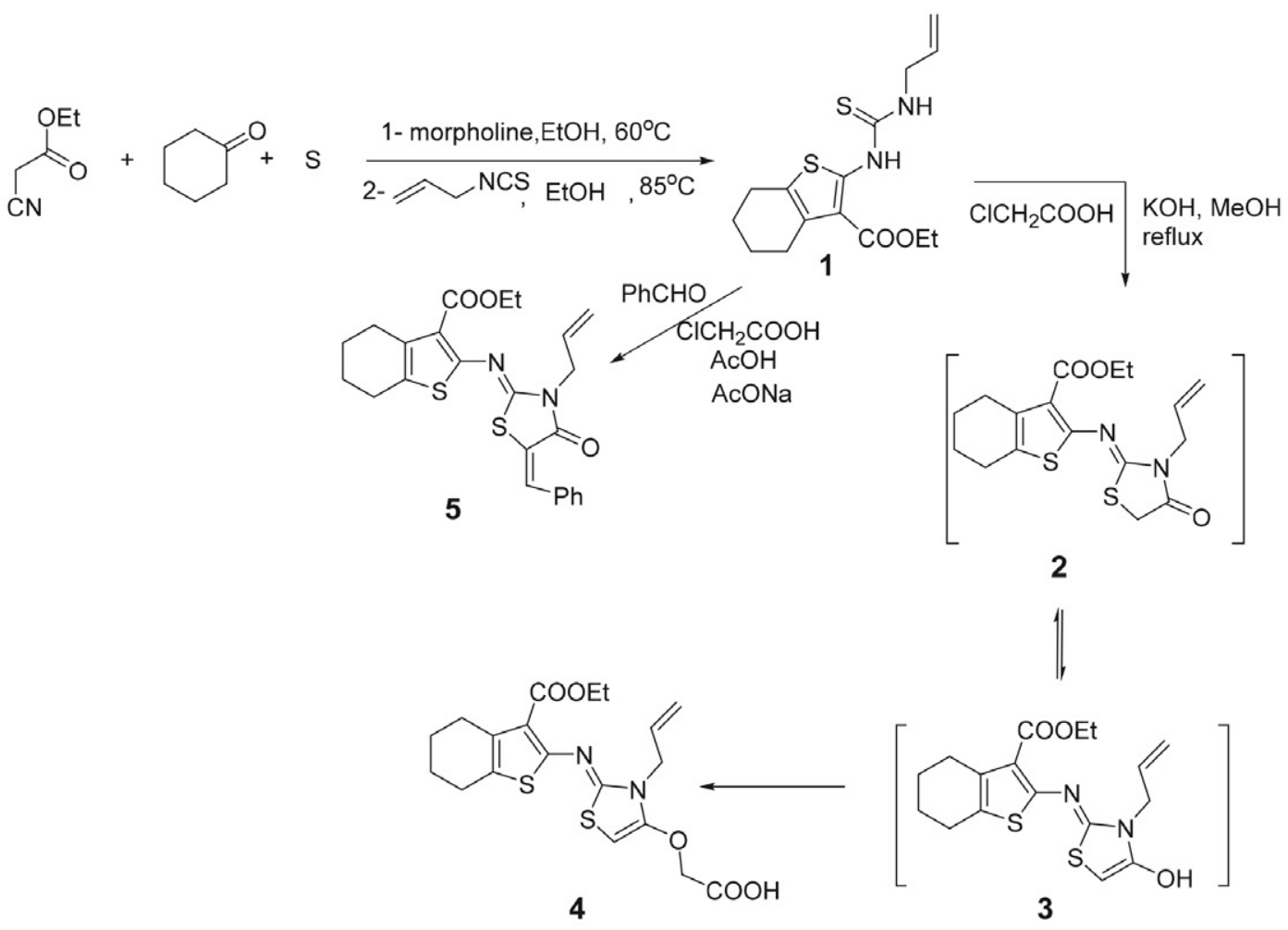

Scheme 1. Synthesis of thiazole derivatives $\mathbf{4}$ and $\mathbf{5}$ by reaction of thiourea derivative $\mathbf{1}$ with monochloroacetic acid under different conditions. 
The resulting pyrimidinone 6 underwent subsequent condensation with corresponding aromatic aldehydes, namely furfural and benzaldehyde and isatin in refluxing ethanol in the presence of piperidine yielding the arylidene derivatives $\mathbf{7 a}, \mathbf{b}$ and $\mathbf{8}$, respectively. Mannich base $\mathbf{9}$ was formed in good yield via Mannich reaction of $\mathbf{6}$ by amino alkylation of its acidic protons which are placed between the two carbonyl groups with para-anisidine and formaldehyde. Further treatment of $\mathbf{6}$ with aryl diazonium chloride obtained from the suitable aromatic amines ( $p a-$ $r a$-toluidine and 4-aminobenzophenone) in pyridine furnished the corresponding hydrazones 10a,b (Scheme 2 ). The spectral and analytical data for compounds $7 \mathbf{a}, \mathbf{b}-$ 10a,b were matching with their expected structures. Their IR and NMR spectra revealed the absence of methylene bands and new bands appeared in accordance with the proposed structures. As well, mass spectra of these synthesized compounds showed molecular ion peaks compatible with their molecular mass.

Ethyl (Z)-2-((1-allyl-4,5-dioxo-4,5-dihydronaphtho[1,2-d]thiazol-2(1H)-ylidene)amino) -4,5,6,7-tetrahydrobenzo[b]thiophene-3-carboxylate (11) was synthesized by the treatment of $\mathbf{1}$ with an equimolar amount of epoxynaphthoquinone derivative $\mathbf{1 1}$ in boiling acetonitrile. The mechanism of its formation is expected to be similar to the one described in previous work. ${ }^{41}$ Condensation of 1 with ninhydrin in acetic acid yielded the corresponding imidazole derivative $\mathbf{1 3}$ (Scheme 3). Structures of 12 and 13 were spectroscopically elucidated. IR spectrum of 12 showed stretching bands at 1689, 1680 and $1668 \mathrm{~cm}^{-1}$ due to the carbonyl of $-\mathrm{COOEt}$ and $2 \mathrm{C}=\mathrm{O}$ of 1,2-quinone. Moreover, its ${ }^{1} \mathrm{H}$ NMR spectrum revealed the presence of aromatic protons at 7.8-8.5 ppm with the other expected signals.

Further reaction of thiourea intermediate $\mathbf{1}$ with benzoyl hydrazide in sodium ethoxide in boiling ethanol afforded the unexpected triazolopyrimidinone $\mathbf{1 4}$ in very good yield. The general mechanism suggested that this reaction proceeds via the formation of the thienopyrimidine 15 followed by condensation and cyclization after the removal of $\mathrm{H}_{2} \mathrm{~S}$ gas. Isolation of $\mathbf{1 4}$ was confirmed; its synthesis utilizing an alternative route by cyclization of compound 1 to give 15 in DMF and in the presence of $\mathrm{KOH}$ with stirring 15 was synthesized previously ${ }^{42}$ with a different method. All spectral and analytical data were compatible with the reported results. Further reaction of 15 with

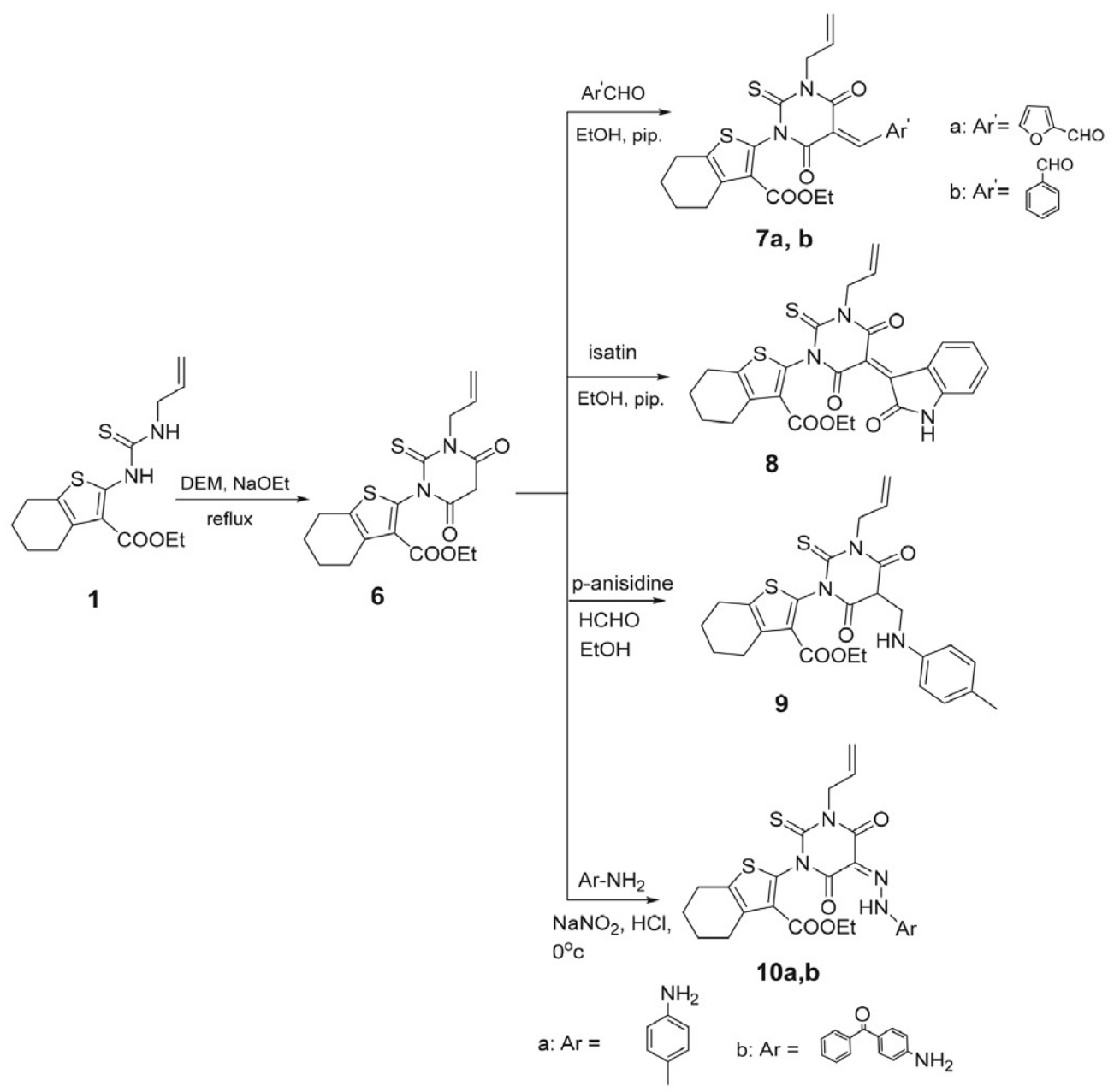

Scheme 2. Synthesis of various pyrimidine derivatives 6-10a,b. 


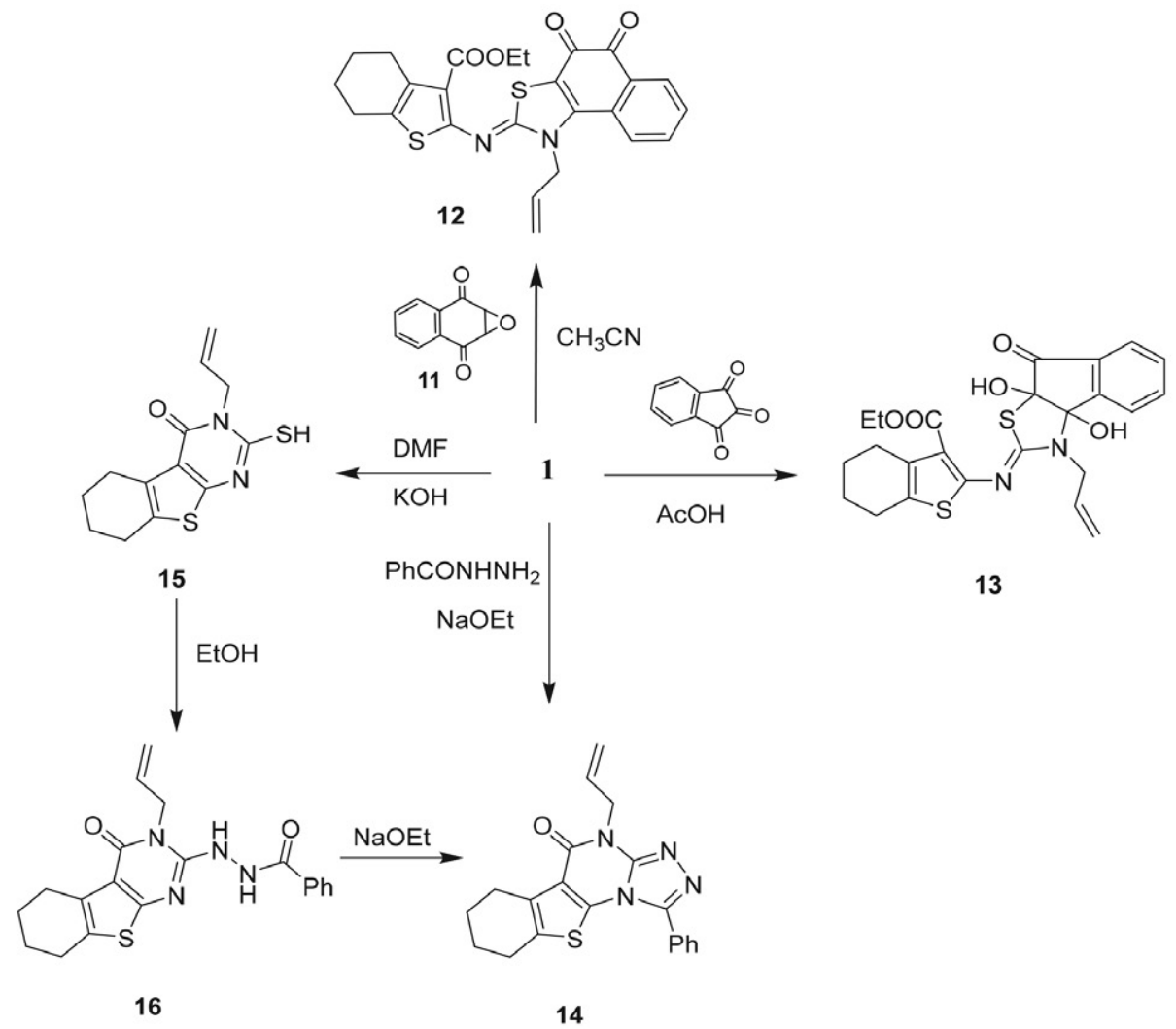

Scheme 3. Synthesis of condensed thiazoles and thienopyrimidine derivatives by treatment of the thiourea dderivative $\mathbf{1}$ with epoxy naphthoquinone, ninhydrin and benzoyl hydrazine, respectively.

benzoyl hydrazide in boiling ethanol led to the formation of $\mathbf{1 6}$ followed by intramolecular cyclization in sodium ethoxide. Structural conformations of compounds 14 and 16 were obtained by their IR, mass and NMR spectra. IR spectra of 14 and 16 lacked the stretching band of ester group and presence of $2 \mathrm{NH}$ stretching bands at 3251, 3397 $\mathrm{cm}^{-1}$ for compound $\mathbf{1 6}$ and disappearance of this band for compound 14. While their ${ }^{1} \mathrm{H}$ NMR spectra affirmed multiplet signals at 7.2-7.8 owing to aromatic protons and the disappearance of -COOEt protons.

Finally, the starting compound $\mathbf{1}$ contains many active sites that led to expect various products. Accordingly, unexpected products were synthesized by treatment of $\mathbf{1}$ with hydrazine hydrate. However, it was observed that when compound $\mathbf{1}$ was treated with hydrazine hydrate in ethanol this resulted in the formation of the thienopyrimidine derivatives $\mathbf{1 7}$ and $\mathbf{1 8}$ which were separated easily from ethanol (Scheme 4). Compound 17 was prepared previously from the reaction of $\mathbf{1 5}$ with hydrazine hydrate in EtOH. The spectral and analytical data of the synthesized thienopyrimidine $\mathbf{1 7}$ were compatible with the reported ones. Evidence of thienopyrimidine 18 was gained from its spectral measurements. Its IR spectrum revealed the presence of $\mathrm{NH}$ stretching band $3239 \mathrm{~cm}^{-1}$ and demised of the ester band. ${ }^{1} \mathrm{H}$ NMR spectrum lacked the signals of -COOEt and allyl protons, in addition, it showed signals at 1.02, 4.17 and $4.37 \mathrm{ppm}$ due to $3 \mathrm{CH}_{2}$ protons.

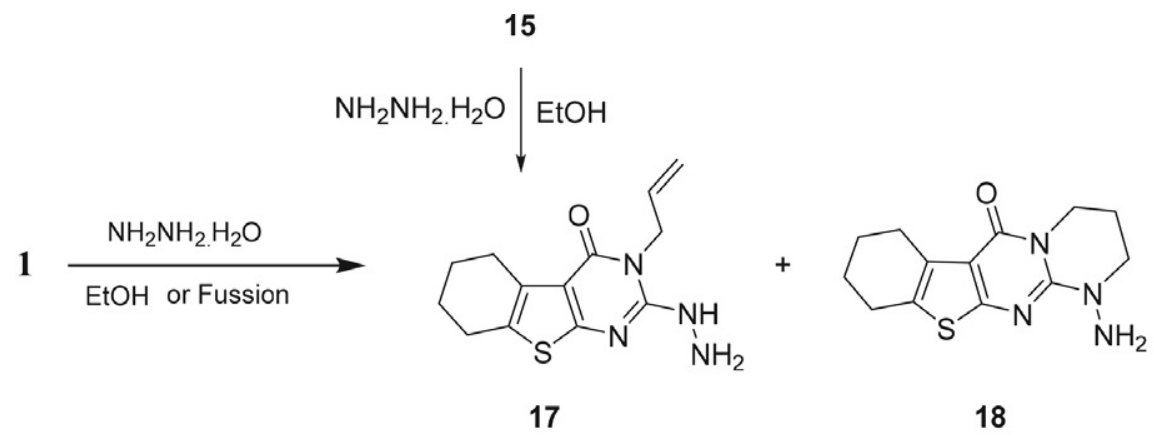

Scheme 4. Treatment of 1 with hydrazine hydrate to afford thienopyrimidines $\mathbf{1 7}$ and $\mathbf{1 8 .}$ 


\section{2. Anticancer Activity}

The newly synthesized compounds 1-18 were preliminarily screened via in vitro anticancer screening in a single high dose $(100 \mu \mathrm{g} / \mathrm{mL})$ concentration against colorectal carcinoma (HCT-116) human cancer cell lines. The efficacy of anticancer activity in comparison to the standard drug 5-fluorouracil and the results of cytotoxic activity are in Table 1. As shown in the table, the majority of the synthesized compounds have low to good anticancer activity versus HCT116 cell line. The obtained results revealed that compounds $6,9,11,12$, and 15 showed the highest activity against the cell line; so these compounds were chosen to test at inhibitory concentration $50 \%\left(\mathrm{IC}_{50}\right)$. The structure-activity relationship according to the results obtained, indicates that incorporation of pyrimidine moieties enhances the anticancer activity of the tested compounds. Compound $\mathbf{6}$ showed the most potent activity, indicating that the presence of the pyrimidinone ring increases the anticancer activity in comparison with pyrimidine moiety. While results for compounds 9 and 10a indicate that the introduction of $p a-$ ra-tolyl substituent with the pyrimidine moiety will increase their anticancer activity. The highest activity of compounds 11 and $\mathbf{1 2}$ is expected to be due to the presence of 1,2-naphthoquinone moieties and two $\mathrm{OH}$ groups, respectively. It is known that introducing amidic group

Table 1. Growth inhibition (\%) of Single Dose Experiment on HCT116 (colon adenocarcinoma) cell line $(100 \mu \mathrm{g} / \mathrm{mL})$ of the synthesized compounds after $72 \mathrm{~h}$ of incubation.

\begin{tabular}{ccc}
\hline Compound. & Surviving \% & Inhibition \% \\
\hline $\mathbf{4}$ & 56.2948 & 43.7052 \\
$\mathbf{5}$ & 53.02419 & 46.97581 \\
$\mathbf{6}$ & 51.07527 & 48.92473 \\
$\mathbf{7 a}$ & 43.21237 & 56.78763 \\
$\mathbf{7 b}$ & 43.6828 & 56.3172 \\
$\mathbf{8}$ & 44.89247 & 55.10753 \\
$\mathbf{9}$ & 35.9543 & 64.0457 \\
$\mathbf{1 0 a}$ & 57.7957 & 42.2043 \\
$\mathbf{1 0 b}$ & 36.96237 & 63.03763 \\
$\mathbf{1 2}$ & 38.44086 & 61.55914 \\
$\mathbf{1 3}$ & 32.25806 & 67.74194 \\
$\mathbf{1 4}$ & 43.6828 & 56.3172 \\
$\mathbf{1 5}$ & 53.0914 & 46.9086 \\
$\mathbf{1 6}$ & 34.27419 & 65.72581 \\
$\mathbf{1 7}$ & 53.76344 & 46.23656 \\
$\mathbf{1 8}$ & 48.3871 & 51.6129 \\
\hline
\end{tabular}

Table $2 \mathrm{IC}_{50}(\mu \mathrm{g} / \mathrm{mL})$ of the more potent tested compounds on HCT-116 (colon adenocarcinoma) cell line.

\begin{tabular}{cc}
\hline Compound & IC $_{\mathbf{5 0}}$ \\
\hline 9 & $44 \pm 1.39$ \\
13 & $9.5 \pm 2.81$ \\
16 & $21 \pm 3.03$ \\
\hline
\end{tabular}

with pyrimidine moiety enhances the anticancer activity in which its structure is similar to the most important anticancer drugs, such as Imatinib; based on that, compounds 12 and 15 showed higher activity."

\section{Conclusion}

In conclusion, a new series of pyrimidines and thiazoles bearing thiophene ring systems were synthesized. Their structures were characterized by spectral data (IR, NMR and mass spectra). Our products were assessed for their anticancer activity against colon HCT-116 human cancer cell line. Among all the synthesized compounds, compounds $6,9,10 \mathrm{a}, 12,13,16$ displayed potent anticancer activity. The rest of compounds showed a moderate to weak activity against the tested tumor cell lines.

\section{References}

1. M. S. A. El-Gaby, Z. H. Ismail, S. M. Abdel-Gawad, H. M. Aly, M. M. Ghorab, Phosphorus Sulfur Silicon Relat. Elem. 2009, 184, 2645-2654. DOI:10.1080/10426500802561096

2. M. M. Ghorab, M. S. Bashandy, M. S. Alsaid, Acta Pharmaceut. 2014, 64, 419-431. DOI:10.2478/acph-2014-0035

3. F. A. Dos Santos, M. C. Pereira, T. B. de Oliveira, F. J. B. Mendonça Junior, M. do C. A. de Lima, M. G. da R. Pitta, I. da R. Pitta, M. J. B. de Melo Rêgo, M. G. da Rocha Pitta, Anti-Cancer Drug. 2017, 1-10.

DOI:10.1097/CAD.0000000000000581

4. M. M. Fouad, E. R. El-Bendary, G. M. Suddek, I. A. Shehata, M. M. El-Kerdawy, Bioorg. Chem. 2018, 81, 587-598. DOI:10.1016/j.bioorg.2018.09.022

5. A. M. Isloor, B. Kalluraya, K. Sridhar Pai, Eur. J. Med. Chem. 2010, 45, 825-830. DOI:10.1016/j.ejmech.2009.11.015

6. L. S. Ming, J. Jamalis, M.Sankaranarayanan, S. Chander, Chem. Data Collect. 2017, 9-10, 104-113.

DOI:10.1016/j.cdc.2017.04.004

7. M. H. Helal, M. A. Salem, M. A. Gouda, N. S. Ahmed, A. A. El-Sherif, Spectrochim. Acta A 2015, 147, 73-83. DOI:10.1016/j.saa.2015.03.070

8. N. N. E. El-sayed, M. A. Abdelaziz, W. W. Wardakhan, R. M. Mohareb, Steroids 2016, 107, 98-111. DOI:10.1016/j.steroids.2015.12.023

9. C. Gopi, M. D. Dhanaraju, Beni-Suef University Journal of Basic and Applied Sciences, 2018, 7, 291-298.

DOI:10.1016/j.bjbas.2018.02.004

10. M. B. Félix, E. R. de Souza, M. do C. A. de Lima, D. K. G. Frade, V. D. L. Serafim, K. A. da F. Rodrigues, P. L. do N. Néris, F. F. Ribeiro, L. Scotti, M. T. Scotti, T. M. de Aquino, F. J. B. Mendonça Jr., M. R. de Oliveira, Bioorg. Med. Chem. 2016, 24, 3972-3977. DOI:10.1016/j.bmc.2016.04.057

11. N. Süleymanoğlu, R. Ustabaş, Y. Ünver, Y. B. Alpaslan, Ş. Direkel, Ü. Karaman, J. Mol. Struct. 2019, 1182, 36-46.

DOI:10.1016/j.molstruc.2019.01.005 
12. T. Harit, R. Bellaouchi, A. Asehraou, M. Rahal, I. Bouabdallah, F. Malek, J. Mol. Struct. 2017, 1133, 74-79.

DOI:10.1016/j.molstruc.2016.11.051

13. L. Pulipati, J. P. Sridevi, P.Yogeeswari, D. Sriram, S. Kantevari, Bioorg. Med. Chem. Lett. 2016, 26, 3135-3140.

DOI:10.1016/j.bmcl.2016.04.088

14. M. S. E 1-Shoukrofy, H. A. Abd El Razik, O. M. AboulWafa, A. E. Bayad, I. M. El-Ashmawy, Bioorg. Chem. 2019, 85, 541-557. DOI:10.1016/j.bioorg.2019.02.036

15. C. Viet, A. Faouzi, C. Barette, A. Farce, M. Fauvarque, T. Lomberget, Bioorg. Med. Chem. Lett. 2016, 26, 174-180. DOI:10.1016/j.bmcl.2015.11.010

16. D. Barnes-Seeman, C. Boiselle, C. Capacci-Daniel, R. Chopra, K. Hoffmaster, C. T. Jones, M. Kato, K. Lin, S. Ma, G. Pan, L. Shu, J. Wang, L. Whiteman, M. Xu, R. Zheng, J. Fu, Bioorg. Med. Chem. Lett. 2014, 24, 3979-3985.

DOI:10.1016/j.bmcl.2014.06.031

17. Y. Xu, S. Yuan, S. Bowers, R. K. Hom, W. Chan, H. L. Sham, Y. L. Zhu, P. Beroza, H. Pan, E. Brecht, N. Yao, J. Lougheed, J. Yan, D. Tam, Z. Ren, L. Ruslim, M. P. Bova, D. R. Artis, Bioorg. Med. Chem. Lett. 2013, 23, 3075-3080.

DOI:10.1016/j.bmcl.2013.03.009

18. L. Li, L. Chang, S. Pellet-Rostaing, F. Liger, Bioorg. Med. Chem. 2009, 17, 7290-7300. DOI:10.1016/j.bmc.2009.08.048

19. A. B. Pinkerton, T. T. Lee, T. Z. Hoffman, Y. Wang, M. Kahraman, T. G. Cook, D. Severance, T. C. Gahman, S. A. Noble, A. K. Shiau, R. L. Davis, Bioorg. Med. Chem. Lett. 2007, 17, 3562-3569. DOI:10.1016/j.bmcl.2007.04.076

20. S. S. Darwish, M. M. Abdel-Halim, Salah, A. H. Abadi, W. Becker, M. Engel, Eur. J. Med. Chem. 2018, 157, 1031-1050. DOI:10.1016/j.ejmech.2018.07.050

21. R. S. Keri, K. Chand, S. Budagumpi, S. B. Somappa, S. A. Patil, B. M. Nagaraja, Eur. J. Med. Chem. 2017, 183, 1002-1033. DOI:10.1016/j.ejmech.2017.07.038

22. Y. Mabkhot, F. Alatibi, N. El-Sayed, S. Al-Showiman, N. Kheder, A.Wadood, A. Rauf, S. Bawazeer, T. Hadda, Molecules 2016, 21, 222-238. DOI:10.3390/molecules21020222

23. D. Gramec, L. Peterlin Mašič, M. S. Dolenc, Chem. Res. Toxicol. 2014, 27, 1344-1358. DOI:10.1021/tx500134g

24. A. V. Medved'ko, V. K. Ivanov, M. A. Kiskin, A. A. Sadovnikov, E. S. Apostolova, V. A.Grinberg, V. V. Emets, A. O. Chizhov, O. M. Nikitin, T. V. Magdesieva, S. A. Kozyukhin, Dyes Pigm. 2017, 140, 169-178. DOI:10.1016/j.dyepig.2017.01.030

25. D. K. Sagdullina, I. E. Kuznetsov, A. V. Akkuratov, L. I. Kuznetsova, Synth. Met. 2019, 250, 7-11.

DOI:10.1016/j.synthmet.2019.01.019

26. B. Chen, J. Zeng, Y. Xiong, H. Nie, W. Luo, Z. Zhao, B. Z. S. Tang, Dyes Pigm. 2018, 159, 275-282.

DOI:10.1016/j.dyepig.2018.04.069
27. H. S. Nassar, Fibers 2015, 4, 102-112. DOI: $10.5923 /$ j.textile.20150405.02

28. S. Al-Mousawi, M. El-Apasery, H. Mahmoud, Molecules 2013, 18, 7081-7092. DOI:10.3390/molecules18067081

29. M. S. Abaee, S. Cheraghi, J. Sulfur Chem. 2014, 35, 261-291. DOI:10.1080/17415993.2013.860141

30. M. A. A. Elneairy, A. E. M.Mekky, A. A. M. Ahmed, J. Sulfur Chem. 2012, 33, 373-383.

DOI:10.1080/17415993.2012.683433

31. F. M. Moghaddam, M. R. Khodabakhshi, A. A. Latifkar, Tetrahedron Lett. 2014, 55, 1251-1254.

DOI:10.1016/j.tetlet.2014.01.014

32. T. Kesharwani, J. Craig, C. Del. Rosario, R. Shavnore, C. Kornman, Tetrahedron Lett. 2014, 55, 6812-6816.

DOI:10.1016/j.tetlet.2014.10.064

33. M. A. Ameen, E. K. Ahmed, J. Sulfur Chem. 2015, 36, $293-$ 299. DOI:10.1080/17415993.2015.1020494

34. A. Doregiraee, K. E. Tavakolinejad, H. Khabazzadeh, B. S. Pouramiri, J. Chil. Chem. Soc. 2015, 60, 3021-3023.

DOI:10.4067/S0717-97072015000300009

35. A. S. Pankova, P. R. Golubev, A. F. Khlebnikov, A. Y. Ivanov, M. A. Kuznetsov, Beilstein J. Org. Chem. 2016, 12, 2563-2569. DOI:10.3762/bjoc.12.251

36. R. Pingaew, S. Prachayasittikul, N. Sinthupoom, V. Prachayasittikul, A.Worachartcheewan, S. Ruchirawat, Mini-Rev. Med. Chem. 2016, 17, 869-901.

DOI: $10.2174 / 1389557516666160923125801$

37. R. Dudhe, P. K. Sharma, P. K. Verma, Org. Med. Chem. Lett. 2014, 4, 3. DOI:10.1186/s13588-014-0003-0

38. T. I. de Santana, M. de O. Barbosa, P. A. T. de M. Gomes, A. C. N. da Cruz, T. G. da Silva, A. C. L. Leite, Eur. J. Med. Chem. 2018, 144, 874-886. DOI:10.1016/j.ejmech.2017.12.040

39. Z. M. Nofal, E. A. Soliman, S. S. Abd El-Karim, M. I. El-Zahar, A. M. Srour, S.Sethumadhavan, T. J. Maher, J. Heterocycl. Chem. 2014, 51, 1797-1806. DOI:10.1002/jhet.1886

40. E. F.Silva-Júnior, E. P. S. Silva, P. H. B. França, J. P. N. Silva, E. O. Barreto, E. B. Silva, R. S. Ferreira, C. C. Gatto, D. R. M. Moreira, J. L.Siqueira-Neto, F. J. B. Mendonça-Júnior, M. C. A. Lima; J. H. Bortoluzzi; M. T. Scotti; L. Scotti, M. R. Meneghetti, T. M. Aquino, J. X. Araújo-Júnior, Bioorg. Med. Chem. 2016, 24, 4228-4240. DOI:10.1016/j.bmc.2016.07.013

41. A. H. Abdel-Rahman, E. M. Kandeel, M. A. Berghot, M. Abdel-Motaal, J. Heterocycl. Chem. 2013, 50, 298-303. DOI:10.1002/jhet.1061

42. M. Kut, M. Onysko, V. Lendel, Heterocycl. Commun. 2016, 22, 347-350. DOI:10.1515/hc-2016-0169

43. A. L. Alanzy, H. H. El-Ganzory, J. Chem. Pharm. Res. 2017, 9, 195-234.

44. T. Mosmann, J. Immunol. Methods 1983, 65, 55-63. 


\section{Povzetek}

Spojino etil 2-(3-aliltioureido)-4,5,6,7-tetrahidrobenzo[b]tiofen-3-karboksilat (1) smo uporabili kot gradnik za sintezo novih heterociklov. Vključitev pirimidinskih in tiazolnih fragmentov smo dosegli s pomočjo kondenzacije spojine $\mathbf{1}$ z različnimi reagenti, kot so kloroocetna kislina, dietil malonat, ninhidrin, 2,3-epoksi-2,3-dihidro-1,4-naftokinon in hidrazin hidrat. Strukture novih produktov smo potrdili s pomočjo spektroskopskih meritev. Za pripravljene produkte smo določili aktivnost proti celični liniji HCT-116 človeškega raka debelega črevesja. Spojine 6, 9, 10a, 11, 12, 15 so izkazale močno aktivnost. 